\title{
Characterization of poly(vinyl chloride) powder produced by emulsion polymerization
}

\author{
Sevdiye Atakul Savrık • Devrim Balköse • \\ Sevgi Ulutan · Semra Ülkü
}

IVMTT2009 Special Chapter

(C) Akadémiai Kiadó, Budapest, Hungary 2010

\begin{abstract}
The effect of emulsion process formulation ingredients on the morphology, structure, and properties of polyvinyl chloride (PVC) powder has been considered in this study. PVC powder was extracted with ethanol and films were obtained by solvent casting from tetrahydrofurane. Characterization of powders, films, and ethanol extract was performed through FTIR spectroscopy, DSC, AFM, SEM, EDX analysis, methylene blue, and nitrogen adsorption. PVC powder was composed of spheres of a large particle size range from $10 \mathrm{~nm}$ to $20 \mu \mathrm{m}$ as shown by SEM. The specific surface area of the PVC powder was determined as 16 and $12 \mathrm{~m}^{2} \mathrm{~g}^{-1}$ from methylene blue adsorption at $25{ }^{\circ} \mathrm{C}$ and from $\mathrm{N}_{2}$ adsorption at $-196{ }^{\circ} \mathrm{C}$, respectively. AFM indicated the surface roughness of the films obtained by pressing the particles was $25.9 \mathrm{~nm}$. Density of PVC powder was determined by helium pycnometry as $1.39 \mathrm{~g} \mathrm{~cm}^{-3}$. FTIR spectroscopy indicated that it contained carbonyl and carboxylate groups belonging to additives such as surface active agents, plasticizers, and antioxidants used in production of PVC. These additives were $1.6 \%$ in mass of PVC as determined by ethanol extraction. EDX analysis showed PVC particles surfaces were coated with carbon-rich materials. The coatings had plasticizer effect since, glass transition temperature was lower than $25^{\circ} \mathrm{C}$ for PVC powder and it was $80^{\circ} \mathrm{C}$ for ethanol extracted powders as found by using differential scanning calorimetry. These additives from polymerization
\end{abstract}

S. A. Savrık · D. Balköse $(\square) \cdot$ S. Ülkü

Chemical Engineering Department, Izmir Institute

of Technology, 35430 Urla, Izmir, Turkey

e-mail: devrimbalkose@iyte.edu.tr

S. Ulutan

Chemical Engineering Department, Ege University, 35100 Bornova, İzmir, Turkey process made PVC powder more thermally stable as understood from Metrom PVC thermomat tests as well.

Keywords Poly(vinyl chloride) .

Emulsion polymerization - Surface area - Density ·

Ethanol soluble additives

\section{Introduction}

Polyvinyl chloride (PVC) is a polymer which can be produced by bulk polymerization, suspension polymerization, and emulsion polymerization. PVC produced by emulsion polymerization is mainly used in producing flexible products such as artificial leather. PVC powder and plasticizes are mixed forming plastisols and by heating them plastigels are obtained. In emulsion polymerization water soluble initiators are applied and polymerization takes place either in the micelles or in water, where always exists a certain amount of solved vinyl chloride monomer (VCM). A typical recipe for emulsion polymerization is "Demineralized water 110-140 parts, Vinyl chloride 100 parts, Emulsifier 0.1-1 parts, Initiator 0.1-0.2 parts". The initiator systems widely used in emulsion polymerization of vinyl chloride are potassium peroxosulfate-sodium bisulfate-copper or iron. One of the most important components of the emulsion polymerization recipe is the emulsifier. The quantity used has a major effect on the final latex particle size achieved, by determining the number of particles initiated. The nature of the emulsifier can also affect the number of particles initiated, particularly at low concentrations. Typical emulsifiers are the sodium salts of alkyl sulfates, alkyl sulfonates, alkylbenzenesulfonates, dialkyl sulfosuccinates, alkyl ethoxysulfates, fatty acid soaps, alkyl phenol ethoxylates, and fatty acid ethoxylates. The structure of the 
particles (agglomerates) formed by removing the water is important in determining the final properties of the plastisol. For this reason a spray drier is normally employed to isolate the solid product. Dried agglomerates of primary PVC particles are collected by cyclone and bag-filter and then usually ground (milling) by pulverizer [1].

The emulsion PVC is used in plastisol production. Molecular mass, amount and type of emulsifier, mean particle size, and particle size distribution of PVC resin effect the rheology of PVC plastisols [2, 3].

PVC is dehydrochlorinated when heated during processing as shown by Eq. 1 .

$$
\begin{aligned}
& -\mathrm{CH}_{2} \mathrm{CHCl}-\mathrm{CH}_{2} \mathrm{CHCl}-\mathrm{CH}_{2} \mathrm{CHCl}-\mathrm{CH}_{2} \mathrm{CHCl} \\
& -\mathrm{CH}_{2} \mathrm{CHCl}-\mathrm{CH}_{2} \mathrm{CHCl}-\mathrm{CH}_{2} \mathrm{CHCl} \longrightarrow-\mathrm{CH}=\mathrm{CH}-\mathrm{CH} \\
& =\mathrm{CH}-\mathrm{CH}=\mathrm{CH}-\mathrm{CH}=\mathrm{CH}-\mathrm{CH}=\mathrm{CH}-\mathrm{CH}=\mathrm{C}-+\mathrm{HCl}
\end{aligned}
$$

Heat stabilizers such as metal soaps, zeolites, antioxidants are added to PVC to prevent dehydrochlorination during processing. As an example substitution of a labile chlorine atom by a carboxylate group of a zinc soap according to Frye and Horst Mechanism is shown in Eq. 2 [4].

$$
\left(\mathrm{RCOO}^{-1}\right)_{2} \mathrm{Zn}+2 \mathrm{R}_{1}-\mathrm{Cl} \longrightarrow 2 \mathrm{RCOOR}_{1}+\mathrm{ZnCl}_{2}
$$

In this study characterization of an emulsion type PVC that was used in our previous research [5-9] on PVC thermal stabilization, PVC-silica composite preparation, biobased plasticizer testing was attempted to be made. For this purpose PVC was extracted with ethanol and films were prepared by solvent casting or dry pressing. Physical and chemical properties of the powders, films, and ethanol extracts were determined by advanced analytical methods.

\section{Experimental}

The PVC powder (PVC p), PETVINYL E38/74 from PETKIM was ethanol extracted for isolating additives from polymerization step. Five g PVC powder was extracted with $300 \mathrm{~cm}^{3}$ ethanol by using a Soxhlet extractor. The extracted powder was dried and called as ethanol extracted powder (EE PVC p). The ethanol phase was dried to obtain ethanol soluble additives. The extractions were done in duplicates to produce EE PVC p1 and EE PVC p2. The additives isolated with ethanol extraction, ethanol extracted PVC and PVC powder itself were attempted to be analyzed in this study. Films were prepared from PVC powder (PVC f), ethanol extracted PVC powder 1 (EE PVC f1), and ethanol extracted PVC powder 2 (EE PVC f2), by solvent casting from tetrahydrofuran.

Surface characterization of emulsion PVC powder was made by adsorption of methylene blue (MB) on PVC, nitrogen adsorption, color test, density measurement, scanning electron microscopy (SEM), dispersive X-ray analysis (EDX), atomic force microscopy (AFM), energy, and Fourier transform infrared spectroscopy (FTIR).

$2,4,6,8,10,12,14,16,18$, and $20 \mathrm{mg} \mathrm{dm}^{-3}$ methylene blue solutions were prepared and $0.2 \mathrm{~g}$ of PVC powder was added to $100 \mathrm{~cm}^{3}$ of each solution. Adsorbed amount of methylene blue was determined after equilbriation in dark at 298 K for 1 week period. Perkin Elmer UV-visible spectrophotometer was used for concentration measurements.

Nitrogen adsorption of PVC samples at $77 \mathrm{~K}$ was taken using micrometrics ASAP 2000.

SEM micrographs of gold coated PVC powder and were taken by a Phillips XL-30S FEG type scaning electron microscope. Chemical composition of the surface was determined by EDX analysis using the same instrument. MMSPM Nanoscope IV type instrument was used for AFM of the films obtained by pressing the PVC powder under 10 tons force. Quantachrome, Ultrapycnometer 1000 is used to determine the density of PVC powder. DSC analysis of PVC powders and ethanol extracts was done by heating the samples at $10{ }^{\circ} \mathrm{C} \mathrm{min}^{-1}$ rate up to $200{ }^{\circ} \mathrm{C}$ using Shimadzu DSC-50 differential scanning calorimeter. FTIR spectra of PVC powder, ethanol extracted powder, and PVC film prepared from tetrahydrofuran by solvent casting were obtained by Shimadzu FTIR 8210 spectrophotometer. Thermal stability of the PVC samples was tested with Methrom 763 PVC Thermomat apparatus.

\section{Results and discussion}

Morphology of powders

Emulsion PVC powders were spherical in shape and small particles are agglomerated on the surfaces of large particles as seen in Fig. 1. There are particles having diameter larger than $20 \mu \mathrm{m}$ and as small as $10 \mathrm{~nm}$.

AFM micrographs of surface of the films obtained by pressing the particles surface in Fig. 2 indicated fusion of the particles under pressure. The particle size of the particles was in the range of $100-500 \mathrm{~nm}$. The surface roughness of the films obtained by pressing the particles was determined to be $26 \mathrm{~nm}$.

\section{Surface area}

Methylene blue adsorption isotherm of the powders at $25{ }^{\circ} \mathrm{C}$ shown in Fig. 3 fitted to Langmuir adsorption model shown in Eq. 3 with a correlation coefficient of 0.98 and Langmuir constants $Q_{\mathrm{m}}$ and $K_{\mathrm{L}}$ were found as $6.18 \mathrm{mg} \mathrm{g}^{-1}$ and $1.36 \mathrm{dm}^{3} \mathrm{mg}^{-1}$, respectively. Assuming MB molecule covers an area of $1.38 \mathrm{~nm}^{2}$ [10] on the surface, the specific 

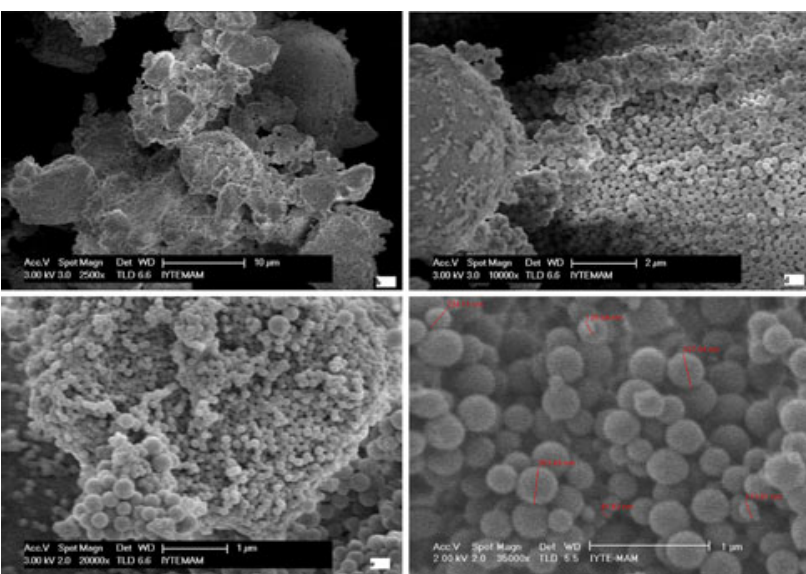

Fig. 1 Micrographs of PVC powder
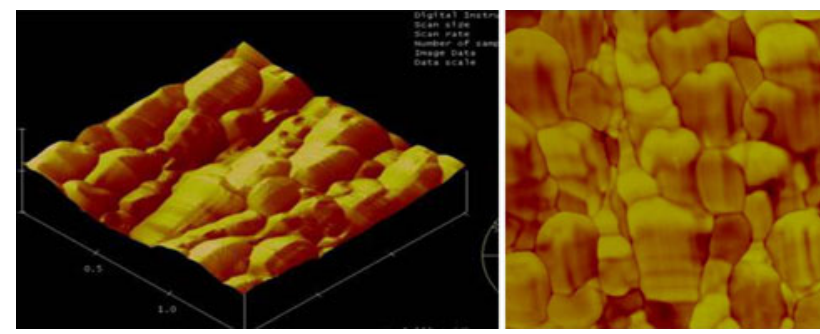

Fig. 2 Top view of PVC powder pellet; left side 3D and right side 2D, scale: $1.5 \mu \mathrm{m}$

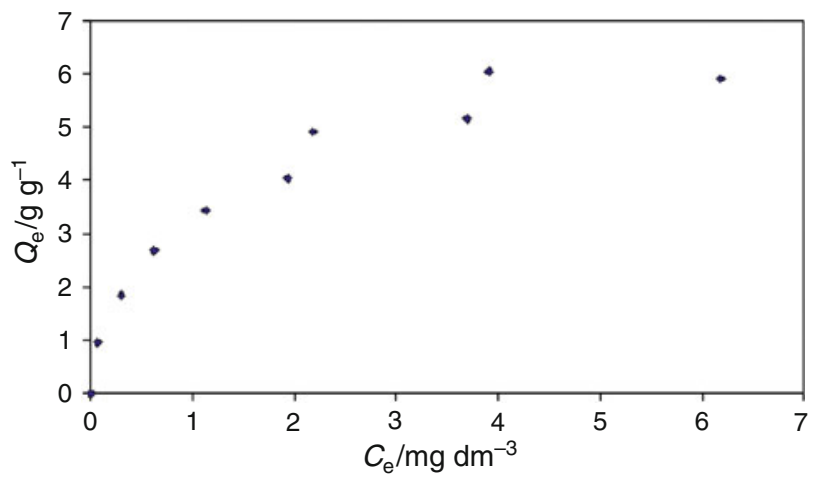

Fig. 3 Adsorption isotherm of methylene blue on PVC powder at $25{ }^{\circ} \mathrm{C}$

surface area of the PVC powder was calculated as $16 \mathrm{~m}^{2} \mathrm{~g}^{-1}$.

$\frac{1}{Q_{\mathrm{e}}}=\frac{1}{Q_{\mathrm{m}}}+\frac{1}{K_{\mathrm{L}} Q_{\mathrm{m}}} \frac{1}{C_{\mathrm{e}}}$

where $K_{\mathrm{L}}=$ Langmuir constant $\left(\mathrm{L} \mathrm{mg}^{-1}\right), Q_{\mathrm{e}}=\mathrm{MB}$ concentration at equilibrium in powder $\left(\mathrm{mg} \mathrm{g}^{-1}\right), C_{\mathrm{e}}=\mathrm{MB}$ concentration at equilibrium in solution $\left(\mathrm{mg} \mathrm{L}^{-1}\right), Q_{\mathrm{m}}=$ MB concentration when monolayer forms onto particle surface $\left(\mathrm{mg} \mathrm{g}^{-1}\right)$.
Nitrogen adsorption isotherm is plotted for volume adsorbed $\left(\mathrm{cm}^{3} \mathrm{~g}^{-1}\right)$ versus relative pressure and given in Fig. 4. While Langmuir model gives $12 \mathrm{~m}^{2} \mathrm{~g}^{-1}$, BET model gives $8 \mathrm{~m}^{2} \mathrm{~g}^{-1}$ surface area for nitrogen adsorption. The surface area values found from methylene blue and nitrogen adsorption are close to each other.

Density of PVC powder was determined by helium pycnometry and average density was $1.39 \mathrm{~g} \mathrm{~cm}^{-3}$. Thus the specific volume of PVC powder, inverse of the density is $0.71 \mathrm{~cm}^{3} \mathrm{~g}^{-1}$. Assuming adsorption occurring on the external surface of the spherical particles and using the surface area and volume of the particles average particle diameters were calculated as 264 and $300 \mathrm{~nm}$ from methylene blue and nitrogen adsorption, respectively.

Elemental composition of surfaces of powders (p) and films (f) on hydrogen free basis shown in Table 1, suggested that PVC particle surfaces were coated by the carbon-rich materials found in emulsion process additives. When the powders were extracted with ethanol the carbon content of the surface was decreased from 80 to $63 \%$ and $71 \%$ in mass for two parallel runs, respectively. The chlorine content of the powder surface (18\%) was much lower than the expected theoretical value of $(60 \%)$. When the powder was extracted with ethanol, chlorine content of the surface increased to 36 and $27 \%$ in mass for two parallel runs, respectively. When films were prepared from PVC powder/PVC $\mathrm{p}$ and PVC powder 1/PVC $\mathrm{p} 1$ extracted with ethanol an even distribution of carbon-rich material was obtained and the carbon/content was decreased to 59

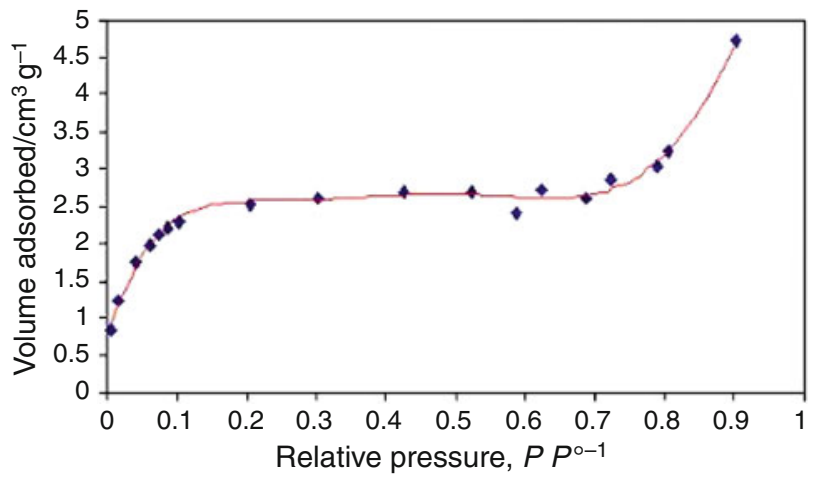

Fig. 4 Adsorption isotherm of nitrogen gas at $-196{ }^{\circ} \mathrm{C}$

Table 1 Elemental composition of PVC surface on hydrogen free basis by EDX analyses, in Mass\%

\begin{tabular}{lrrrrrr}
\hline Element & Theoretical & $\begin{array}{l}\text { PVC } \\
\text { p }\end{array}$ & $\begin{array}{l}\text { EE PVC } \\
\text { p1 }\end{array}$ & $\begin{array}{l}\text { EE PVC } \\
\text { p2 }\end{array}$ & $\begin{array}{l}\text { PVC } \\
\text { f1 }\end{array}$ & $\begin{array}{l}\text { PVC } \\
\text { f2 }\end{array}$ \\
\hline $\mathrm{C}$ & 40 & 80 & 63 & 71 & 59 & 51 \\
$\mathrm{O}$ & 0 & 2 & 1 & 2 & 2 & 2 \\
$\mathrm{Cl}$ & 60 & 18 & 36 & 27 & 39 & 47 \\
\hline
\end{tabular}


and $51 \%$ in mass, respectively, and the chlorine content was increased to 39 and $47 \%$, respectively.

Figure 5a shows the FTIR spectrum of PVC powder. The peaks in the region of $600-700 \mathrm{~cm}^{-1}$ correspond to $\mathrm{C}-\mathrm{Cl}$ stretching vibrations. These peaks are of complex origin and depend on the conformational structure of the polymer and the spatial position of the atoms surrounding the $\mathrm{C}-\mathrm{Cl}$ bonds. The peak at $2920 \mathrm{~cm}^{-1}$ corresponds to $-\mathrm{CH}_{2}-$ and $-\mathrm{CH}-$ stretching groups. The two peaks at 1257 and 1321 coresspond to $-\mathrm{CH}$ in $-\mathrm{CHCl}$ stretching groups [8]. The FTIR spectrum of ethanol extract in Fig. 5b had carbonyl streching vibrations at $1740 \mathrm{~cm}^{-1}$ and carboxylate streching vibrations at $1540 \mathrm{~cm}^{-1}$. Thus the ethanol extract which possibly consists of surface active agents, plasticizers, and antioxidants used in emulsion polymerization must have carbonyl and carboxlate groups. The amount of these additives was $1.6 \%$ of PVC, as determined by ethanol extraction.

DSC curves of PVC p, EE PVC p1, and EE PVC p2 shown in Fig. 6 indicated that while the glass transition point of PVC powder was below room temperature, the extracted powders had $80{ }^{\circ} \mathrm{C}$ glass transition temperature. The additives used in emulsion polymerization of PVC acted as plasticizers and lowered the glass transition temperature. When these additives were removed by ethanol extraction the glass transition temperature of pure PVC was observed. DSC curves of the waxy ethanol extract 1 and 2
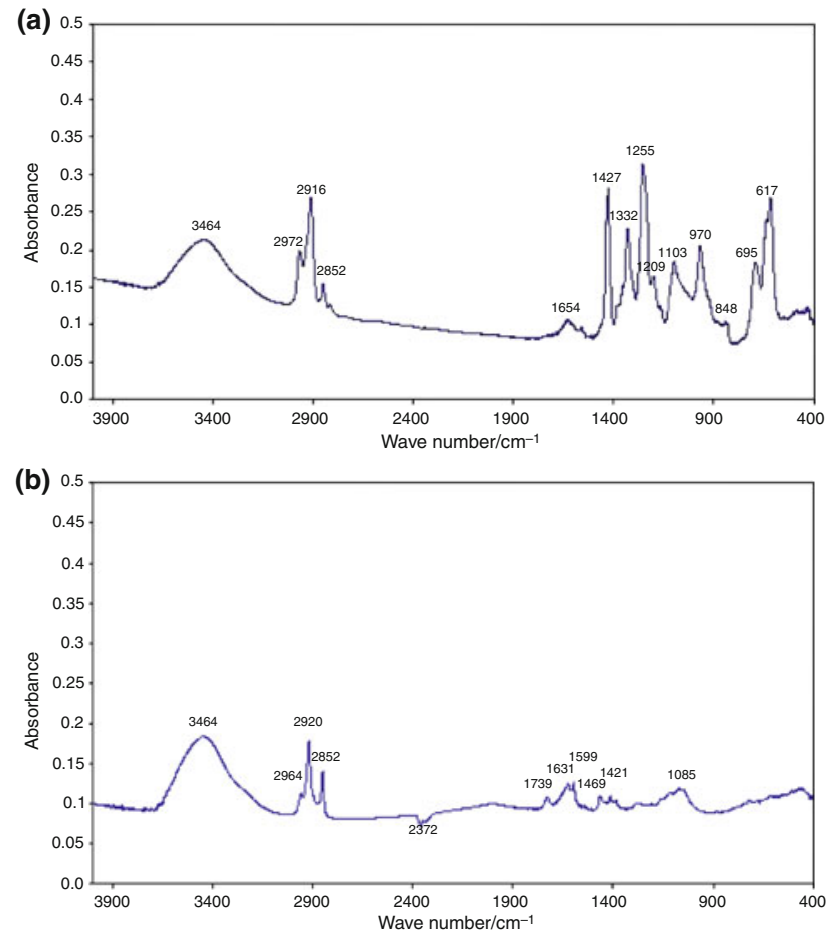

Fig. 5 FTIR spectra of a PVC powder (PVC p), b ethanol extract 1 (EE 1)

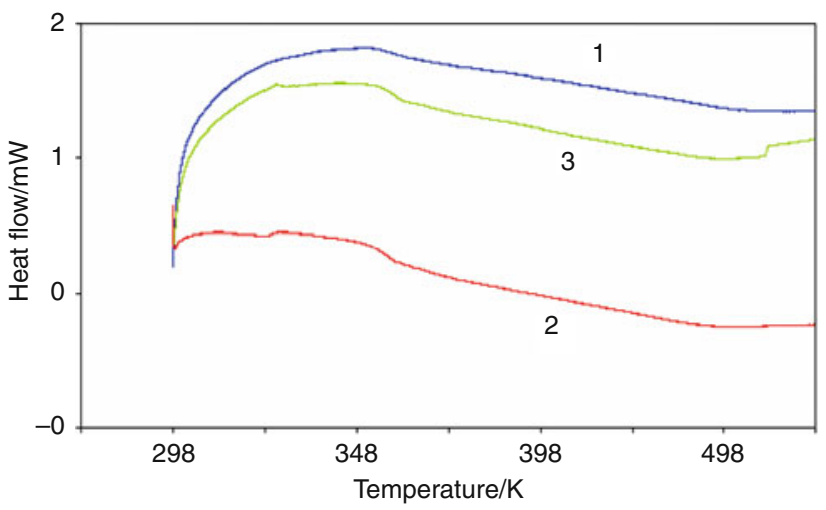

Fig. 6 DSC curves of 1 PVC powder, 2 ethanol extracted PVC-1I, 3 ethanol extracted PVC 2 (1 PVC p, 2 EE PVC p1, 3 EE PVC p2)

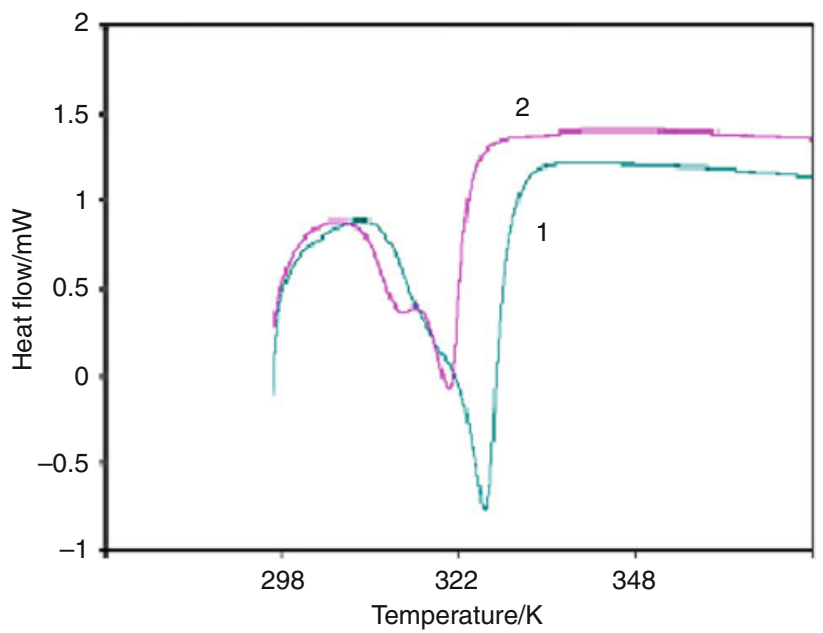

Fig. 7 DSC curves of 1 ethanol extract 1, 2 ethanol extract 2

in Fig. 7 indicated they had a melting endotherm being maximum at 45 and $55^{\circ} \mathrm{C}$, respectively.

Effect of emulsion polymerization additives on PVC thermal stability

PVC thermomat tests of PVC powders and films gave information about dehydrochlorination reactions occurring on heating. The released $\mathrm{HCl}$ gas is carried by nitrogen gas through a conductivity cell filled with water. $\mathrm{As} \mathrm{HCl}$ dissolves in water the conductivity increases. In Fig. 8 conductivity of water versus time are given for samples heated at $140{ }^{\circ} \mathrm{C}$. The point at which the conductivity starts to increase is defined as the induction time and the conductivity reaches to $50 \mu \mathrm{S} \mathrm{cm}{ }^{-1}$ is called as the stability time. In Figs. 9 and 10 induction and stability times for samples heated at 140 and $160{ }^{\circ} \mathrm{C}$ are shown. Induction and stability times were shorter at $160{ }^{\circ} \mathrm{C}$ than $140{ }^{\circ} \mathrm{C}$. Dehydrochlorination reaction studied by thermal gravimetry indicated that its activation energy was constant as 


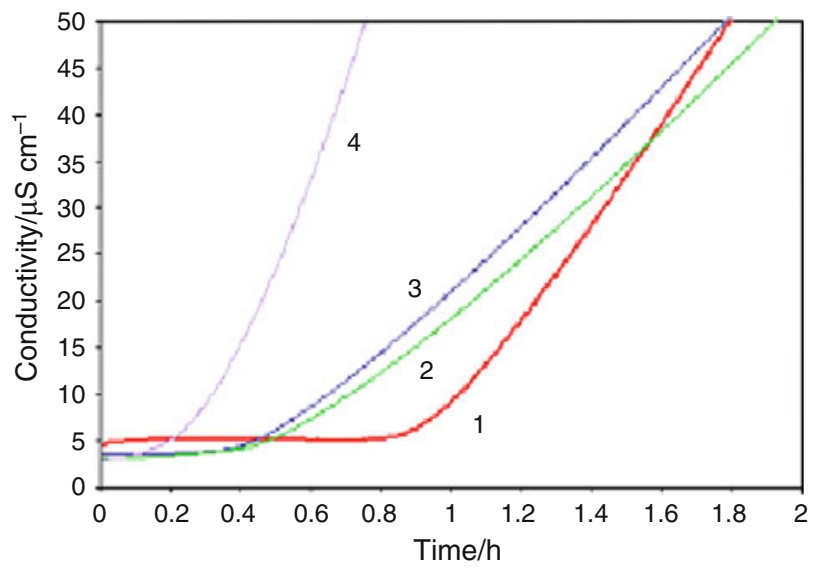

Fig. 8 PVC thermomat test results of 1 PVC powder, 2 ethanol extracted PVC-1, 3 ethanol extracted PVC-2, and 4 cast film from PVC powder (1 PVC p, 2 EE PVC p1, 3 EE PVC p2, and 4 PVC f)

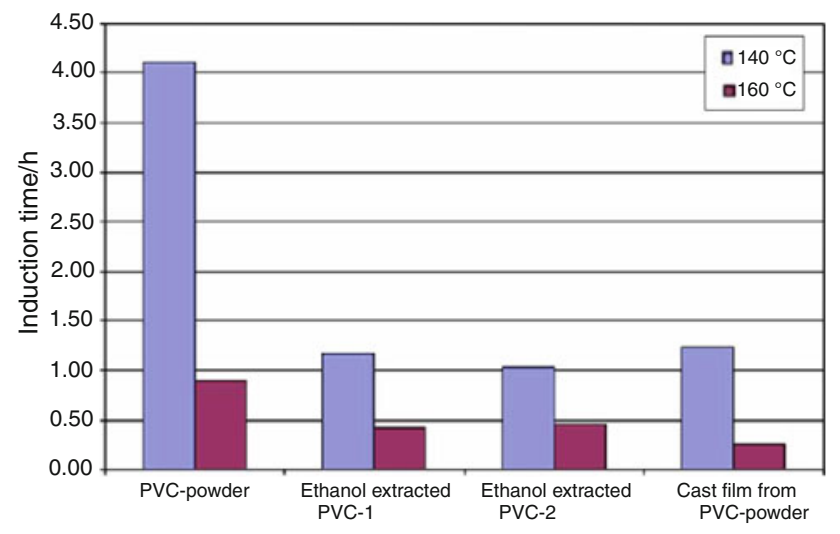

Fig. 9 Induction times of PVC samples

$102 \mathrm{~kJ} \mathrm{~mol}^{-1}$ for the conversion range of $0.05-0.7$ [11]. Induction time indicates the time of release of $\mathrm{HCl}$ from the samples to the environment. As seen in Figs. 8 and 9 induction time of PVC powder was higher than the ethanol extracted powders and PVC film prepared from PVC powder. This result suggests that the emulsion process additives which possibly coated the surface of PVC particles act as barrier to $\mathrm{HCl}$ evolution and retard the transfer of $\mathrm{HCl}$ from the bulk to the surrounding. Therefore, the removal of coating in extraction process or becoming looser on the surface after film casting may render the induction time shorter. When the coating was removed by extraction or when the coating material distributed evenly in the bulk of PVC induction time decreased.

On the other hand the stability times of unextracted and extracted powders were very close to each other. This indicated once the barrier layer was passed by hydrogen chloride molecules formed by dehydrochlorination, no further mass transfer resistance remains behind. Similar behavior was observed when heat stabilizers, zeolites, and

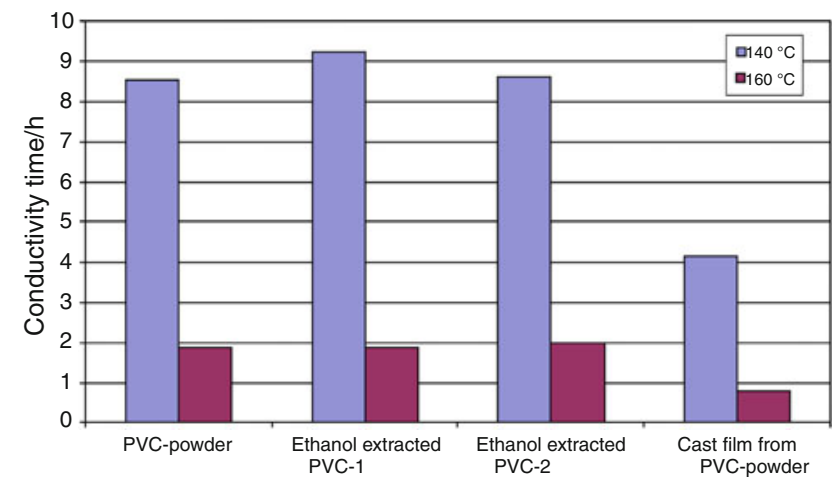

Fig. 10 Stability times of PVC samples

zinc soaps were added to PVC powder. Longer stability and induction times were observed for PVC powder without stabilizers [9]. This fact could be explained by the/ depleation and tearing of the coated layer on the surface of the powder due to the mechanical forces exerted during mixing process of stabilizers and PVC powder.

\section{Conclusions}

PVC powder having $1.39 \mathrm{~g} \mathrm{~cm}^{-3}$ density was composed of spheres of a large particle size range $20 \mu \mathrm{m}$ and as small as $10 \mathrm{~nm}$ as shown by SEM. AFM indicated the surface roughness of the films obtained by pressing the particles was $25.9 \mathrm{~nm}$. The specific surface area of the PVC powder was determined as 16 and $12 \mathrm{~m}^{2} \mathrm{~g}^{-1}$ from methylene blue adsorption at $298 \mathrm{~K}$ and from $\mathrm{N}_{2}$ adsorption at $-196 \mathrm{~K}$, respectively. Emulsion process additives used in production of PVC which have carbonyl and carboxylate groups and act as surface active agents, plasticizers, and antioxidants of PVC was $1.6 \%$ in mass. EDX analysis and DSC showed PVC particle surfaces were coated with waxy carbon-rich materials. The coatings had plasticizer effect since the glass transition temperature was lower than $25^{\circ} \mathrm{C}$ for PVC powder and it was $80^{\circ} \mathrm{C}$ for ethanol extracted powders. As understood from PVC thermomat tests, these additives originating from polymerization process made PVC powder more thermally stable, as well.

Acknowledgements $\quad$ M. C. Y1lmaz, F. Potur, F. Üstün, and B. Alp are gratefully acknowledged for their contribution to experimental study.

\section{References}

1. Saeki Y, Emura T. Technical progress for PVC production. Prog Polym Sci. 2002;27:2055-131.

2. Borroso EG, Duarte FM, Couto M, Maria JM. A rheological study of aging of emulsion and microsuspension based PVC plastisols. J Appl Polym Sci. 2008;109:664-73. 
3. Rasteiro MG, Tomas A, Ferreira L, Figuredo S. PVC paste rheology: study of process dependencies. J Appl Polym Sci. 2009;112:2809-21.

4. Frye AH, Horst RW. J Polym Sci. 1959;40:419.

5. Ulutan S, Balkose D. Diffusivity, solubility and permeability of water vapor in flexible PVC/silica composite membranes. J Memb Sci. 1996;115:217-24.

6. Demir H, Sipahioglu M, Balkose MD, Ulku S. Effect of additives on flexible PVC foam formation. J Mater Process Technol. 2008;195:144-53.

7. Balkose D, Egbuchunam TO, Okeimen FE. Formulation and properties' evaluation of $\mathrm{PVC} /($ dioctyl phthalate)/(epoxidized rubber seed oil) plastigels. J Vinyl Addit Technol. 2008;14:65-72.
8. Egbuchunam D, Balkose TO, Okeimen FE. Effect of zinc soaps of rubber seed oil (RSO) and/or epoxidised rubber seed oil (ERSO) on the thermal stability of PVC plastigels. Polym Degrad Stab. 2007;92:1572-82.

9. Savrik BC, Erdogan SA, Balkose D, Ulku S. Statistical thermal stability of PVC. J Appl Polym Sci. 2010;116:1811-22.

10. Kipling JT. Adsorption from solutions of non-electrolytes. London: Academic Press; 1965.

11. Budrugerac P. The Kissinger law and IKP method for evaluating the non-isothermal kinetic parameters. J Them Anal Calorim. 2007;89:143-51. 